\title{
Simultaneous detection of food safety hazards (Salmonella enterica and Listeria monocytogenes) in table eggs using multiplex PCR
}

\author{
(D) C. O. Vinayananda ${ }^{a}$, Mohamed Nadeem Fairoze ${ }^{b}$, C. B. Madhavaprasad ${ }^{c}$ and Nagappa S. K.
}

\begin{abstract}
${ }^{a}$ Research Scholar, Department of Livestock Products and Technology, Veterinary College, Bengaluru-560024, Karnataka, INDIA

'Professor and Head, Department of Livestock Products and Technology, Veterinary College, Bengaluru-560024, Karnataka, INDIA

'Assistant Professor, Department of Veterinary Public Health \& Epidemiology, Veterinary College, Shivamogga, 577203, Karnataka, INDIA.

'Professor, Department of Veterinary Public Health \& Epidemiology, Veterinary College, Gokula Campus, Vidyanagar, Hassan - 573 201, Karnataka, INDIA.
\end{abstract}

Corresponding author: C. O. Vinayananda | email: vinvet22@gmail.com

Co-authors: MNF: prof.nadeem@gmail.com ; CBM: cbmadhava@rediffmail.com ; NSK: pub.nag@gmail.com

Received: 19-10-2020, Accepted: 29-11-2020, Published online: 21-12-2020

\section{Abstract}

Foods are analyzed for food safety hazards in order to comply with food safety standards. Among foodborne pathogens Salmonella enterica and Listeria monocytogenes are recognized as major foodborne pathogens of public health significance worldwide. In the present study, multiplex polymerase chain reaction (mPCR) was used to screen for S. enterica and L. monocytogenes in table eggs collected from different markets (840 eggs). Pooled egg samples categorized as commercial and backyard eggs based on the source of collection. Collected eggs were screened for S. enterica and L. monocytogenes using mPCR assays. Conserved regions viz. invA and prfA genes were targeted for the specific detection of S. enterica and L. monocytogenes, respectively. mPCR and conventional method showed same results, prevalence of $S$. enterica at 12.5 and 33.3 per cent in commercial and backyard eggs, respectively. While, L. monocytogenes was undetectable in commercial eggs; but, detected only in backyard table egg sample (8.3\%). Present study indicated complete concordance between specific pre-enrichment mPCR and conventional cultural methods. Results of the study underscored mPCR as steadfast rapid tool for the screening of table eggs for listed food safety hazards $S$. enterica and L. monocytogenes in table eggs.

Keywords: Eggs; Listeria; mPCR; Public Health; Salmonella

\footnotetext{
doi: www.doi.org/10.51128/jfas.2020.A018 | How to cite this article: Vinayananda, C. O., Fairoze, M. N., Madhavaprasad, C. B., and Nagappa S. K. 2020. Simultaneous detection of food safety hazards (Salmonella enterica and Listeria monocytogenes) in table eggs using multiplex PCR. Journal of Food and Animal Sciences, 01(02): 98 - 103.

Copyright: Vinayananda, et al. Open Access. This article is distributed under the terms of the Creative Commons Attribution 4.0 International License (http://creativecommons.org/licenses/by/4.0/), which permits unrestricted use, distribution, and reproduction in any medium, provided you give appropriate credit to the original author(s) and the source, provide a link to the Creative Commons license, and indicate if changes were made. The Creative Commons Public Domain Dedication waiver (http://creativecommons.org/publicdomain/zero/1.0/) applies to the data made available in this article, unless otherwise stated.
} 


\section{Introduction}

Salmonella enterica and Listeria monocytogenes are the major food safety hazards of public health concern often implicated in foodborne disease outbreaks (Singh et al., 2012). Salmonellosis, caused by Salmonella enterica, a disease of economic significance having implications on the food industry and it is primarily associated with poultry and poultry products. Genus Salmonella comprises of over 2,600 serovars and it is the second largest cause of food poisoning in the world (Gal-Mor et al., 2014); Salmonellae can also be transmitted from animals to humans through food; occasionally, person to person transmission also occurs through the faeco-oral route in addition to prevalent sporadic cases and it also cause severe extra-intestinal infections such as bacteremia and meningitis (Borges et al., 2018). Salmonellae gets transmitted vertically among poultry, has longer persistence in the environment and poultry products are often contaminated with Salmonellae (Afshari et al., 2018). Likewise, L. monocytogenes is a ubiquitous gram-positive bacterium widespread in the environment such as soil, water, animal gut, etc. L. monocytogenes grows over wide $\mathrm{pH}$ (4.39 to 9.40) range, refrigeration temperatures and is associated with listeriosis in human and animals (Singh et al., 2012). Among 17 Listeria species, L. monocytogenes has been identified as the most significant member owing to its pathogenic nature to humans and animals responsible for food-borne infections, meningitis, encephalitis and febrile gastroenteritis (Barbuddhe $e t$ al., 2002).

A rapid and sensitive method for detection of these pathogens will be absolutely useful for taking decision at field level about acceptance or the rejection of table egg lots. In the last decade, molecular techniques have appeared as most promising alternatives than conventional cultural methods in food microbiology. Conventional culture methods require series of procedure which consumes more time and are laborious. In such cases, use of molecular-based techniques thwart the delay and permits to detect the pathogens with greater sensitivity and reliability than conventional culture methods (Germini et al., 2009; Rattanachaikunsopon and Phumkhachorn, 2012). A rapid and sensitive assay like polymerase chain reaction (PCR) based method for identification of the food borne pathogens is proven and even several pathogens can be detected in a single reaction by multiplex PCR or mPCR (Soumet et al., 1999).

Therefore, present study was designed with the objectives of simultaneous detection of S. enterica and $L$. monocytogenes using $\mathrm{MPCR}$ assay targeting invA and $\operatorname{prf} A$ genes respectively and comparison of $\mathrm{mPCR}$ with that of conventional method.

\section{Materials and Methods}

Sample collection: Table egg (360) were collected from different markets comprising of commercial layer farms (240) and backyard rearing (120) systems. Egg samples were collected from retail markets into sterile polybags and transported to the laboratory immediately. Samples were collected on four occasions at an interval of 15 days and analyzed for $S$. enterica and L. monocytogenes using the multiplex PCR.

Sample preparation: Pool of ten eggs selected from each batch were surface sterilized with $70 \%$ ethanol, broken under aseptic conditions and whole egg contents were mixed in bag for 3 minutes using stomacher (Bagmixer ${ }^{\circledR}$, Interscience). Ten milliliters of resultant egg homogenates were then transferred into two separate sterile polybags containing 90 milliliters of buffered peptone water (BPW) or half Fraser Broth (hFB) for the primary enrichment (1:9) of $S$. enterica or L. monocytogenes, respectively. Bags containing BPW or hFB were mixed well in stomacher for 4 minutes and incubated at $37^{\circ} \mathrm{C}$ and $30^{\circ} \mathrm{C}$ for 24 hours for Salmonella and Listeria, respectively.

DNA isolation from primary enrichment: DNA was extracted from pre-enriched samples using snap chill method (Manoj et al., 2014). Briefly, $2 \mathrm{~mL}$ preenriched broth (BPW or hFB) were centrifuged at 6,000 rpm for 10 minutes; resultant pellet containing bacterial cells was washed with sterile phosphate buffered saline and re-suspended in $50 \mu \mathrm{L}$ nuclease free water. After boiling for $100{ }^{\circ} \mathrm{C}$ for 10 minutes, putative suspensions were subjected for one freezethaw cycle $\left(-20{ }^{\circ} \mathrm{C}\right.$ for $15 \mathrm{~min}$.). Thawed suspension was centrifuged at $6,000 \mathrm{rpm}$ for 10 minutes and supernatant collected into a fresh tube was used as template DNA for PCR.

Detection of S. enterica and L. monocytogenes in primary en richment broth by PCR: For the detection of S. enterica and $L$. monocytogenes in the primary enrichment broth (BPW/hFB) multiplex PCR assay performed targeting 
invA (invasion 'A' gene) of S. enterica (Rahn et al., 1992) and prfA (transcriptional activator of virulence factor) of L. monocytogenes (Wernars et al., 1992) as described by Germini et al., (2009) with minor modifications.

Multiplex PCR was performed in $25 \mu \mathrm{L}$ volume comprised of $12.5 \mu \mathrm{L}$ of 2 Xmaster mix (Himedia ${ }^{\circledR}$ ), $0.5 \mu \mathrm{L}$ of each primers [Salmonella genus specific invA gene primers 5'-AAT TAT CGC CAC GTT CGG GCA A-3' and 5'-TCG CAC CGT CAA AGG AAC C-3'; L. monocytogenes specific prfA primers 5'-TCA TCG ACG GCA ACC TCG G -3' and 5'TGA GCA ACG TAT CCTCCA GAG T-3'], $3 \mu l$ template DNA $(1.5 \mu \mathrm{l}$ each) and $7.5 \mu \mathrm{l}$ of DNase free water. The mPCR amplification program consisted of initial denaturation for $5 \mathrm{~min}$ at $95^{\circ} \mathrm{C}, 40$ cycles of denaturation $\left(95^{\circ} \mathrm{C}, 60 \mathrm{~s}\right)$, annealing $\left(54^{\circ} \mathrm{C}, 40 \mathrm{~s}\right)$ and elongation $\left(72^{\circ} \mathrm{C}, 50 \mathrm{~s}\right)$; followed by the final elongation at $72^{\circ} \mathrm{C}$ for $4 \mathrm{~min}$. Amplified products were resolved in agarose gel (1.5\%) and ethidium bromide stained amplicons were visualized under short-wavelength UV light source and photographed. Standard cultures of S. Enteritidis (ATCC 13076) and L. monocytogenes (MTCC 1143) were used for the standardization of mPCR.

Isolation and identification of $S$. enterica and $L$. monocytogenes: Samples showing positive by MPCR amplicons from the primary enrichment were subjected for conventional cultural isolation of $S$. enterica species and L. monocytogenes as per standard protocols (ISO 6579:2002 and ISO 11290:1998). Identification of $S$. enterica species and L. monocytogenes was carried out using a battery of biochemical tests (Blodgett, 2010).

\section{Results and Discussion}

Presence of S. enterica and L. monocytogenes was detected based on the amplification of the 284 and
217 base pairs PCR products in Salmonella and Listeria species, respectively (Figure 1). Among the table egg samples screened using the mPCR, Salmonella and Listeria were detected in 19.4 and 2.7 per cent, respectively. Distribution of these food safety hazards among different categories of table egg samples is given in Table 1. Occurrence of S. enterica was highest in backyard eggs followed commercial table eggs. Primary enrichment samples of commercial eggs were found negative for $L$. monocytogenes using $\operatorname{prf} A$ gene based mPCR. However, one sample of backyard eggs showed amplification for $\operatorname{prf} A$ gene.

Use of cultural media and methodology for detection and isolation of pathogens will vary and even sensitivity is also low and difficult to detect non-viable cells or injured cells of pathogens by cultural method, but they may have potential to recover and grow when the food is consumed, therefore molecular assay may be more appropriate. Several simplex or multiplex PCR assays have been developed for the rapid detection of of Salmonella and Listeria species using specific primers (Germini et al., 2009; Manning et al., 2015; Liu et al., 2015; Afshari et al., 2018; Heymans et al., 2018; Dzieciol et al., 2016). Of the several amplification targets used for detection of Salmonella such as agf A, fimA, viaB, fliC- $\mathrm{d}$, virulence-associated plasmids, etc the invA gene has been one of the most widely gene targets for the specific detection of Salmonellae (Phumkhachorn and Rattanachaikunsopon, 2017; Afshari et al., 2018; Heymans et al., 2018; Borges et al., 2018). Likewise, L. monocytogenes could be specifically detected using virulence factors such as actin polymerization protein (actA), phosphatidylinositol phospholipase C ( $p l c A)$, hemolysin $(h l y A)$ and invasive associated protein (iap) genes that are involved in the pathogenesis (Liu et al., 2015; Dzieciol et al., 2016); of these, prfA has been the accepted target for the specific detection of $L$.

Table 1: Detection of Salmonella enterica and Listeria monocytogenes in eggs using mPCR

\begin{tabular}{|c|c|c|c|}
\hline Egg source & Egg samples analyzed $^{\#}$ & S. enterica & L. monocytogenes \\
\hline Commercial layer farms & 24 & $3(12.5 \%)$ & ND \\
\hline Backyard & 12 & $4(33.3 \%)$ & $1(8.3 \%)$ \\
\hline Total & $\mathbf{3 6}$ & $\mathbf{7 ( 1 9 . 4 \% )}$ & $\mathbf{1}(\mathbf{2 . 7} \%)$ \\
\hline
\end{tabular}

\#Each sample consists pool of 10 eggs; ND- Not detected. 


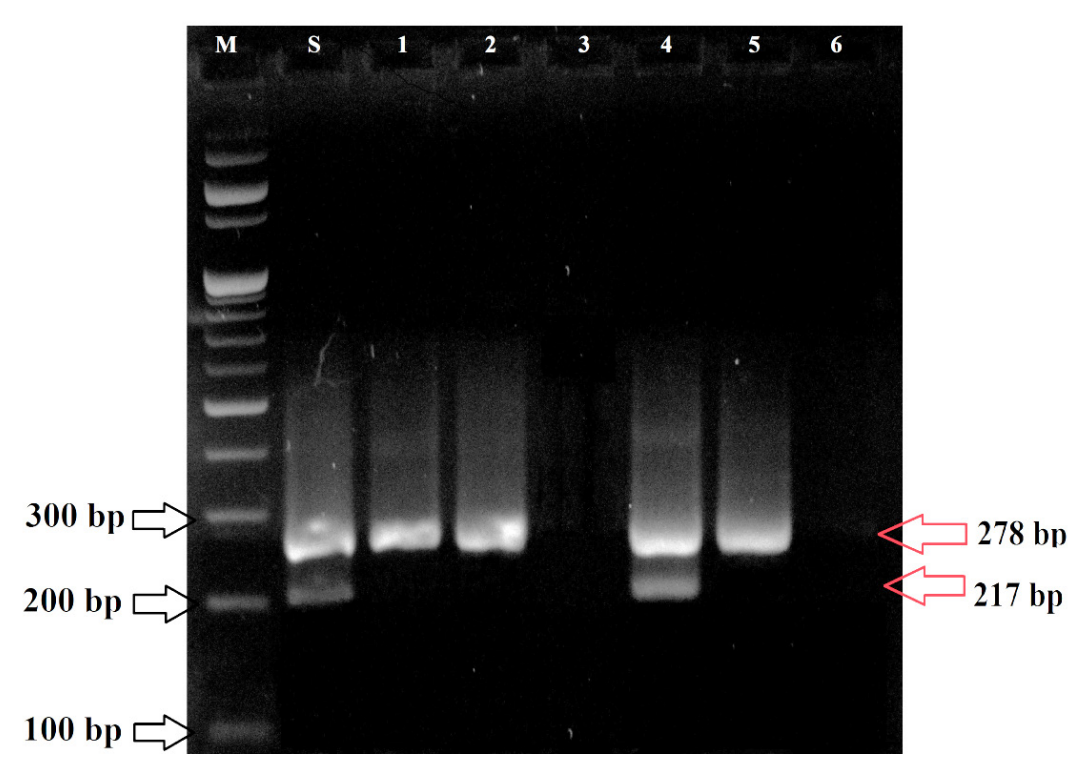

Figure. 1: Multiplex PCR assay for screening of S.enterica (invA gene-278 bp) L. monocytogenes (prfA-217 bp)

M- 100 bp ladder, S-Standard (S. Typhimurium and L. monocytogenes), Lane 1 to 5 samples; Lane 6- NTC

monocytogenes (Wernars et al., 1992).

The mPCR adopted in the present study was found to detect both pathogens simultaneously and the results of the mPCR were in complete concordance with the conventional cultural methods. However, separate primary enrichment broth for Salmonella and Listeria monocytogens is preferred over universal primary enrichment medium while screening for pathogens in food samples using mPCR, where Salmonella will predominant over the Listeria monocytogens multiplication irrespective of initial counts (Jofre et al., 2005).

Similar studies by other investigators could detect few pathogen (Nagappa et al., 2007; Gole et al., 2013, Vinay et al., 2016; Rajashekhara et al., 2017) or have shown discrepancies (Al-Obaidi et al., 2011; Safaei et al., 2011; Paul et al., 2016). The mPCR employed in the present study with minor modification was found reliable for the simultaneously detection of two major food safety hazards in table eggs with an anticipation of food safety compliance. Keeping in view, the limitations of laborious and time consuming conventional cultural methods, results of the present study support to propose application of mPCR is for the rapid and specific detection of S. enterica and Listeria monocytogenes in table eggs. Nevertheless, multi-centric validations involving large samples are warranted for the wide scale acceptance of results.

\section{Conclusions}

The applications of PCR have revolutionized the molecular diagnostics including detection of food safety hazards. In the present study, mPCR assay adopted for the rapid and simultaneous detection of $S$. enterica and L. monocytogenes in table egg contents. The results of the mPCR were in complete concordance with the conventional cultural methods. Therefore, the mPCR assay has been proposed as alternative tool for the rapid and simultaneous detection of S. enterica and $L$. monocytogenes in table eggs for the purpose of food safety compliance testing of samples.

\section{Authorship contribution statement}

VinayanandaC.O.:Conceptualization, Methodology, Formal analysis, Investigation, Writing - original draft

Nadeem Fairoze: Conceptualization, Writing review \& editing, Visualization, Supervision, Funding acquisition.

C. B. Madhavaprasad: Conceptualization, Writing original draft, Writing - review \& editing.

Nagappa S. K: Methodology, Data curation, Writing original draft, Writing - review \& editing.

\section{Acknowledgments}

All the authors acknowledge and thank to Karnataka Veterinary, Animal and Fisheries Sciences University, BIDAR 


\section{Funding}

None.

\section{Declaration of Competing Interest}

All authors declare that there exist no commercial or financial relationships that could, in any way, lead to a potential conflict of interest.

\section{Reference}

Afshari, A., A. Baratpour, S. Khanzade, A. and Jamshidi 2018. Salmonella Enteritidis and Salmonella Typhimorium identification in poultry carcasses. Iran. J. Microbiol. 10(1): 45 .

Al-obaidi, F. A., S. M. Al-shadeedi, R. H. and Aldalawi, 2011 Center, Quality, chemical and microbial characteristics of table eggs at retail stores in Baghdad. Int. J. Poult Sci., 10(5): 381-385.

Barbuddhe, S. B., S. P. Chaudhari and S. V. S. Malik. 2002. The occurrence of pathogenic Listeria monocytogenes and antibodies against listeriolysin-O in buffaloes. J. Vet. Med., Series $B$, 49(4): 181-184.

Blodgett, 2010. Bacteriological analytical manual. US Food and Drug Administration.

Borges, K. A., T. Q. Furian, S. N. De souza, R. Menezes, D. A. De lima, F. B. B. Fortes and V. P. Nascimento 2018. Biofilm formation by Salmonella Enteritidis and Salmonella Typhimurium isolated from avian sources is partially related with their in vivo pathogenicity. Microb. Pathog., 118: 238-241

Dzieciol, M., E. Schornsteiner, M. MuhteremUyar, B. Stessl, M. Wagner, S. and SchmitzEsser 2016. Bacterial diversity of floor drain biofilms and drain waters in a Listeria monocytogenes contaminated food processing environment. Int. J. Food Microbiol. 223: 3340 .

Gal-mor, O., E. C. Boyle, G. A. Grassl. 2014. Same species, different diseases: how and why typhoidal and non-typhoidal Salmonella enterica serovars differ. Front Microbiol. 5,
391.

Germini, A., A. Masola, P. Carnevali, R. and Marchelli 2009. Simultaneous detection of Escherichia coli O175: H7, Salmonella spp., and Listeria monocytogenes by multiplex PCR. Food Control. 20(8): 733-738

Gole, V. C., K. K. Chousalkar, and J. R. Roberts. 2013. Survey of Enterobacteriaceae contamination of table eggs collected from layer flocks in Australia. Int. J. Food Microbiol. 164(2-3): 161-165.

Heymans, R., A. Vila, Van Heerwaarden, C., Jansen, C., Castelijn, G., Van Der Voort, M. and E. G. Biesta-Peters. 2018. Rapid detection and differentiation of Salmonella species, Salmonella Typhimurium and Salmonella Enteritidis by multiplex quantitative PCR. PloS one 13(10): e0206316

Jofre, A., B. Martin, M. Garriga, M. Hugas, M. Pla, D. Rodríguez-Lázaro and T. Aymerich. 2005. Simultaneous detection of Listeria monocytogenes and Salmonella by multiplex PCR in cooked ham. Food Microbiol. 22(1): 109-115

Liu, H., L. Lu, Y. Pan, X. Sun, C. A. Hwang, Y. Zhao and V. C. Wu. 2015. Rapid detection and differentiation of Listeria monocytogenes and Listeria species in deli meats by a new multiplex PCR method. Food Control. 52: 7884

Manning, J., V. Gole and K. Chousalkar. 2015. Screening for Salmonella in backyard chickens. Prev. Vet. Med. 120(2): 241-245.

Manoj, J. R, K. Agarwal, B. Sailo, M. A. Wani, K. Ashok, K. and Dhama, M. K. Singh. 2014. Comparison of PCR and conventional cultural method for detection of Salmonella from poultry blood and faces. Asian. J. Anim. Vet. Adv. 9(11): 690-701

Nagappa, K., Tamuly, S., Saxena, M. K, Brajmadhuri and Singh, S. P. 2007. Isolation of Salmonella Typhimurium from poultry eggs and meat of Tarai region of Uttaranchal. Indian J Microbiol. 6: 407-409.

Paul, N. F., C. Kennedy, S. V. O. and Shoyinka. 2016. Molecular Detection of Salmonella Isolated 
from Poultry Farms in Abia State Southeast Nigeria. Int. J. Curr. Microbiol. App. Sci. 5(7): 961-968.

Phumkhachorn, P. and P. Rattanachaikunsopon. 2017. Detection of Viable Salmonella Typhi Using Three Primer Pairs Spescific to Inva, Ivab, and Flic-D Genes. Emir. J. Food Agric. 312-316.

Rahn, K., S. A. De Grandis, R. C. Clarke, S. A. Mcewen, J. E. Galan, C. Ginocchio and C. L. Gyles. 1992. Amplification of an invA gene sequence of Salmonella Typhimurium by polymerase chain reaction as a specific method of detection of Salmonella. Mol. Cell. Probes. 6(4): 271-279

Rajashekhara, D. B., M. N. Fairoze, N. Karabasanavar, C. B. Madhavaprasad, A. G. Shilpa, A. M. kotresh and P. Nadoor. 2017. Molecular detection and antibiogram of virulent Salmonellae isolated from chicken meat. Indian J. Anim. Sci. 87(2): 1208-1211

Rattanachaikunsopon, P. and P. Phumkhachorn. 2012. Identification of viable Listeria species based on reverse transcription-multiplex PCR (RT-mPCR) and restriction digestion. Biosci. Biotechnol. Biochem. 76(6): 1189-1194

Rivoal, K., S. Quéguiner, E. Boscher, S. Bougeard, G. Ermel, G., Salvat, Michel Federighi, Florence Jugiau and J. Protais. 2010. Detection of Listeria monocytogenes in raw and pasteurized liquid whole eggs and characterization by PFGE. Int. J. Food Microbiol. 138(1-2): 56-62.

Safaei, G. H., M. Jalali, A. Hosseini, T. Narimani,
A. Sharifzadeh and E. Raheimi 2011. The prevalence of bacterial contamination of table eggs from retails markets by Salmonella spp., Listeria monocytogenes, Campylobacter jejuni and Escherichia coli in Shahrekord, Iran. Jundishapur J. Microbiol. 4(4): 249-254

Singh, J., V. K. Batish, S. and Grover. 2012. Simultaneous detection of Listeria monocytogenes and Salmonella spp. in dairy products using real time PCR-melt curve analysis. J. Food Sci. Technol. 49(2): 234-239

Soumet, C., G. Ermel, N. Rose, V. Rose, P. Drouin, G. Salvat and P. Colin. 1999. Evaluation of a multiplex PCR assay for simultaneous identification of Salmonella sp., Salmonella Enteritidis and Salmonella Typhimurium from environmental swabs of poultry houses. Lett. Appl. Microbiol. 28(2): 113-117.

Vinay K. B. N., F. Nadeem, C. B. Madhavaprasad, K. Nagappa, A. M. Kotresh, N. Prakash, S. B Prashant, A. G. Shilpa, S. B. Barbuddhe, K. Nitin, C. and Sandeep. 2016. Molecular characterization and antibiogram of Listeria monocytogenes isolated from chicken and mutton of retail markets. J. Microbiol. Infect. Dis. 6(2): 65-68.

Wernars, K., K. Heuvelman, S. Notermans, E. Domann, M. Leimeister-Wächter and T. Chakraborty. 1992. Suitability of the prfA gene, which encodes a regulator of virulence genes in Listeria monocytogenes, in the identification of pathogenic Listeria spp. Appl. Environ. Microbiol. 58(2): 765-768. 